\title{
Quantitative Proteomics Using ITRAQ Labeling and Mass Spectrometry
}

\author{
H. R. Fuller ${ }^{1,2}$ and G. E. Morris 1,2 \\ ${ }^{1}$ Wolfson Centre for Inherited Neuromuscular Disease, \\ RJAH Orthopaedic Hospital, Oswestry \\ 2Institute for Science and Technology in Medicine, Keele University \\ UK
}

\section{Introduction}

Proteomics research involves the identification and characterisation of proteins in order to elucidate their function and interactions with other proteins. Since the composition of protein mixtures can vary between cell types and can change under certain physiological conditions, one aim is often to quantify up- or down-regulation of individual proteins. Characterisation of proteomic changes associated with disease often helps to shed light on disease mechanisms and identify useful biomarkers and therapeutic targets. It is rarely the case that such proteins are either "present" or "absent", but more likely that they vary in abundance to different degrees. It is therefore important to have a sensitive and accurate method to measure these changes using an unbiased approach.

Shotgun proteomics approaches enable identification of proteins that are up-regulated or down-regulated under specific conditions and this can be studied in different cell and tissue lysates. Isobaric tags for relative and absolute quantification (iTRAQ ${ }^{\mathrm{TM}}$ ) make it possible to both identify and quantify proteins simultaneously. iTRAQ ${ }^{\mathrm{TM}}$ can easily be multiplexed, enabling analysis of up to 8 different samples within the same experiment. Our objectives in this chapter are to place iTRAQ ${ }^{\mathrm{TM}}$ (isobaric tags for relative and absolute quantification) in context in the history of attempts to bring quantitative studies to proteomics, to explain what it can do, to describe in some detail the protocol that we use in this laboratory and to illustrate the application of $\mathrm{iTRAQ}^{\mathrm{TM}}$ to medical and clinically-relevant problems, including our own work on the proteomic effects of common drug treatments.

\section{A brief history of quantitative proteomics}

Over the last two decades, the emergence of vast genomic databases has completely revolutionized the way in which mass spectrometry is used to analyze proteins. Many proteins are now well represented in databases, and their annotations are increasingly becoming more detailed to include information such as sites of post-translational modification. However, this information is only qualitative, which means that differential comparisons of protein expression in a perturbed system, with reference to "control" proteins in a database, are not yet possible. It is possible, however, to perform parallel comparisons of protein expression in different systems using approaches that require staining or labeling of proteins. 
The traditional 2-dimensional gel approach, where differentially expressed stained spots are excised and identified by mass spectrometry has many limitations. The wide range of protein abundance often obscures low abundance proteins and not all types of proteins are amenable to gel electrophoresis. Reproducibility is often an issue due to gel-dependent variation and this means that quantitation is often difficult and unreliable (reviewed by Issaq and Veenstra, 2008).

Shotgun proteomics methods involving isotope labeling of proteins have been developed during the last decade and overcome some of the difficulties associated with quantification using gel-based approaches (Wu et al., 2005). One strategy, called SILAC (stable isotope labeling by amino acids in cell culture), involves metabolic incorporation of specific amino acids into proteins (Ong et al., 2002). Two cell populations are grown in culture media that are identical except that one of them contains a 'light' and the other a 'heavy' form of a particular amino acid (e.g. ${ }^{12} \mathrm{C}$ and ${ }^{13} \mathrm{C}$ labeled L-lysine, respectively). Both samples are combined after the cells are harvested and the proteins are identified by mass spectrometry. Metabolic incorporation of the amino acids into the proteins results in a mass shift of the corresponding peptides and the ratio of peak intensities in the mass spectrum reflects the relative protein abundance. Whilst SILAC is a highly efficient technique, a major drawback is that it relies on endogenous labeling of cell lines, so it is not suitable for use with primary tissue such as patient samples (e.g. muscle and serum).

Another strategy, Isotope Coded Affinity Tags (ICAT®), is a cysteine specific, protein-based labeling strategy designed to compare two different sample states (Gygi et al., 1999). One sample is labeled with a light isotope and the other with a heavy isotope, and then the samples are combined and analyzed by mass spectrometry. The ratios of signal intensities of the ICAT-tagged peptide pairs are quantified to determine the relative levels of proteins in the two samples. The specificity of ICAT reagents for cysteine residues means that the approach is sometimes preferred because it reduces sample complexity. However, this also creates a drawback in that peptides lacking cysteine residues will not be labeled, so many important peptides, including those with post-translational modifications (PTMs) will be discarded.

Isobaric tagging strategies overcome some of the major limitations of isotope tagging. One such method was developed by Applied Biosystems (now AB Sciex) and is called iTRAQ ${ }^{\mathrm{TM}}$ : isobaric tags for relative and absolute quantification (Ross et al., 2004). The reagents were originally designed for the simultaneous multiplexed analysis of up to 4 samples, but are now available as an 8-plex kit (Choe et al., 2007). The iTRAQTM tags react with all primary amines of peptides, which means that all peptides are labeled and information about their post-translational modifications are retained. The isobaric nature of the tags also means that the same peptide from each of the samples being compared appears as a single peak in the mass spectrum. This reduces the complexity of the data when compared to isotopic labeling strategies where "heavy" and "light" versions of each peptide are detected in each mass spectrum.

\section{3. $\operatorname{ITRAQ}^{\mathrm{TM}}$ : Isobaric tags for relative and absolute quantification}

\section{1 iTRAQ $^{\mathrm{TM}}$ reagent chemistry}

The iTRAQ ${ }^{\mathrm{TM}}$ tags are isobaric labels that react with primary amines of peptides including the $\mathrm{N}$-terminus and $\varepsilon$-amino group of the lysine side-chain. Each label has a unique charged reporter group, a peptide reactive group, and a neutral balance group to maintain an overall 
mass of $145 \mathrm{Da}$ (Figure 1). When a peptide is fragmented by MS/MS fragmentation, the iTRAQTM reporter groups break off and produce distinct ions at $m / z 114,115,116,117,118$, 119,121 and 122. The relative intensities of the reporter ions are directly proportional to the relative abundances of each peptide in the samples that being compared. In addition to producing strong reporter ion signals for quantification, MS/MS fragmentation of iTRAQ ${ }^{T M}$-tagged peptides also produces strong $y$ - and b-ion signals for more confident identification. During the design of the iTRAQ ${ }^{\mathrm{TM}}$ tags, the reporter ion masses were carefully selected in order to minimize interference from noise in the low mass region such as matrix ions, immonium and fragment ions. This is the reason that the 8-plex reagents skip from 119 to 121 , since the phenylalanine immonium ion appears at $m / z 120$.

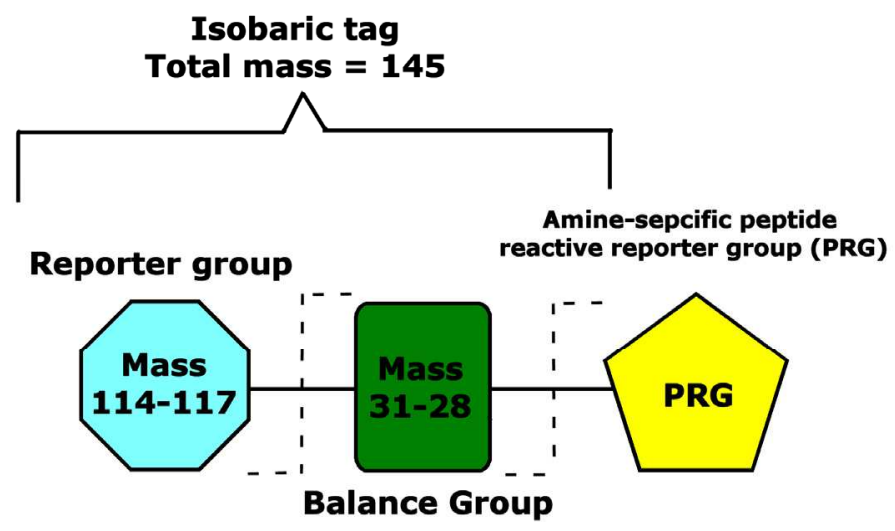

Fig. 1. Structure of the iTRAQTM reagents.

Each isobaric tag has a unique charged reporter group, a peptide reactive group, and a neutral balance group to maintain an overall mass of $145 \mathrm{Da}$.

\section{2 iTRAQ ${ }^{\mathrm{TM}}$ work-flow}

The general workflow for an iTRAQTM experiment with 4 tags is shown in Figure 2. Each sample is reduced, alkylated, and digested with trypsin. Each set of peptides is then labeled with a different one of the 4 (or 8) iTRAQ ${ }^{\mathrm{TM}}$ tags, pooled, separated by liquid chromatography (LC), and the resulting fractions are analysed using mass spectrometry.

\subsection{Digging deeper}

It is not always essential to separate proteins before digestion, but some form of fractionation will be needed in order to detect relatively-low abundance components. A simple one-dimensional LC separation of peptides from a whole proteome will overwhelm the mass spectrometer, and highly abundant peptides will mask detection of others. By separating proteins and/or peptides in more than one dimension, it starts to become possible to "see the wood for the trees". Multidimensional protein identification technology (MudPIT) is a common technique for whole proteomic analysis such as iTRAQ ${ }^{\mathrm{TM}}$ comparisons, and can be performed off-line or coupled directly to the mass spectrometer (Washburn et al., 2001). There are many choices of chromatography techniques, including affinity chromatography, ion exchange chromatography, reversed-phase chromatography and size-exclusion chromatography. 
A

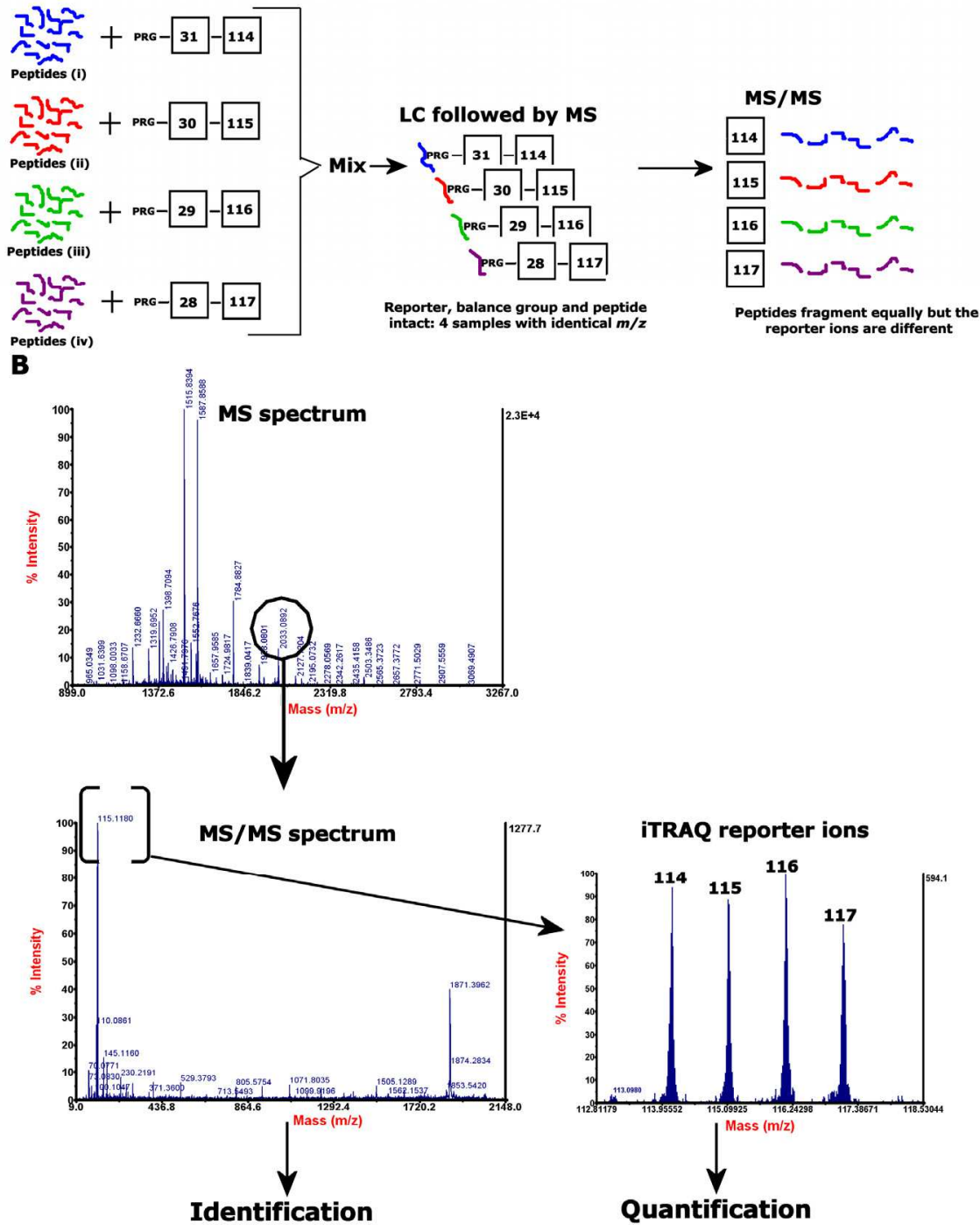

Fig. 2. A general scheme and example data for a 4-plex iTRAQ experiment.

A. Based on a figure by Zieske (2006), this illustration shows the general scheme of a 4-plex iTRAQ experiment. Each of the four sets of peptides are labeled with one of the iTRAQ reagents, mixed together and separated by liquid chromatography. In MS analysis, each identical peptide from the four sets appears as a single precursor (the iTRAQ balance group ensures that all tags have the same overall $\mathrm{m} / \mathrm{z}$ ). Following fragmentation in MS/MS, the iTRAQ reporter ions break off and their relative intensities are used for quantification. Each of the four peptides fragments in the same way and give rise to $\mathrm{b}$ - and $\mathrm{y}$-ions for identification.

B. shows some example MS and MS/MS data, with an expanded view of the low-mass region of the MS/MS spectrum to show the resolved ITRAQ reporter ions. 
Even after LC separation in two dimensions, we are still only able to scratch the top $10-20 \%$ of the surface of complex mammalian proteomes using standard instrumentation (Fuller et al., 2010). For a global, unbiased view of the proteome, this is a good starting point and can often yield clues to follow up further. If particular types of low abundant proteins are of interest then enrichment such as subcellular fractionation or immunodepletion of abundant proteins will be necessary.

\subsection{Instrumentation}

Matrix-assisted laser desorption ionisation (MALDI) MS/MS and electrospray ionisation (ESI) MS/MS are the most common types of mass spectrometer used for iTRAQTM analysis, and there have been several comparisons of the two types of instrument for accuracy and performance of iTRAQTM quantification. Shirran and Botting (2010) analysed a fixed concentration of a six-protein mix and concluded that MALDI MS/MS gave the most accurate results. In contrast, two other studies where more complex biological samples were analysed concluded that analyses by MALDI and ESI are comparable in terms of accuracy and performance (Kuzyk et al., 2009 and Scheri et al., 2008). Whilst it is possible to re-analyse archived LC-separated samples by MALDI MS/MS (and so has the potential to yield more data), the trade-off is that MALDI analysis usually takes longer than ESI analysis.

Under standard MS/MS fragmentation (collision-induced dissociation (CID)), an ion trap is unable to analyze small product ions because of their low mass cut-off limitation. This meant that traditionally, iTRAQ ${ }^{\mathrm{TM}}$-based quantification was not possible using an ion trap or hybrid instrument containing an ion trap such as the LTQ-Orbitrap. Recently developed fragmentation methods now make it possible to perform iTRAQ ${ }^{\text {TM}}-$ based quantification on an LTQ-Orbitrap and include Pulsed Q Dissociation (PQD) (Bantscheff et al., 2008) and higher energy C-trap dissociation (HCD) (Zhang et al., 2009). Both fragmentation methods are less suited for protein identification at a proteomic scale than CID fragmentation, but when combined with CID, HCD allows sensitive and accurate iTRAQ ${ }^{\mathrm{TM}}$ quantification of whole proteomes (Köcher et al., 2009).

\subsection{Accuracy of iTRAQ ${ }^{\mathrm{TM}}$-based quantification}

There are many reports in the literature that demonstrate the reliability of iTRAQTM to measure changes spanning up to two orders of magnitude accurately on MALDI and ESI platforms using low- and high-complexity protein mixtures (Fuller et al., 2010, Scheri et al., 2008 and Yang et al., 2007). Even in whole proteome protein mixtures, it is possible to achieve good correlation between iTRAQ ${ }^{\mathrm{TM}}$ ratios and those measured biochemically by methods such as quantitative western blotting and immunofluorescence microscopy, providing appropriate statistical analysis of the iTRAQ ${ }^{\mathrm{TM}}$ data is carried out (Fuller et al., 2010).

There are, however, instances where this is not the case. Low-signal data have higher relative variability, irrespective of the instrumentation used (Karp et al., 2010). Since low abundance proteins are usually detected with fewer peptides, they are often disregarded from datasets when statistics-based filtering approaches are used. Several bioinformaticsbased models have been suggested to help resolve this problem about heterogeneity of variance, and include an additive-multiplication error model for peak intensities (Karp et al., 2010) and IsobariQ software that employs variance stabilizing normalization (VSN) algorithms (Arntzen et al., 2011). 
There are also an increasing number of reports that there is a degree of underestimation of iTRAQTM ratios, seen especially with larger changes (Ow et al., 2009, Karp et al., 2010 and Ow et al., 2011). "Ratio compression", as it has been termed, is thought to arise from several factors including isotopic contamination and background interference. Providing accurate isotope factors are available, it is possible to correct for impurities from chemical enrichment and natural isotope abundance in the iTRAQ ${ }^{\mathrm{TM}}$ reagents using data processing software (e.g. this is a standard function in GPS Explorer software, AB Sciex). The bigger problem arises from background interference: if two peptides have a very similar $m / z$ and cannot be resolved by the mass spectrometer during precursor ion selection, the resulting MS/MS spectrum will contain fragment ions and iTRAQ ${ }^{\mathrm{TM}}$ reporter ions from both peptides. One of the two peptides may be identified using this data, but its iTRAQTM ratios may have been "diluted" by those arising from the other peptide. This issue is currently very difficult to minimise but it has been suggested that it can be partly alleviated using high-resolution sample fractionation (Ow et al., 2011).

\section{Example protocol for ITRAQ $^{\mathrm{TM}}$ analysis using a MALDI TOF/TOF}

The following protocol is one we routinely use for analysis of iTRAQTM samples on an AB Sciex 4800 MALDI-TOF/TOF instrument, but the method could be used with other mass spectrometers since we have omitted any instrument-specific information.

\subsection{Cell / tissue extraction}

- Extract cell pellets in 10 volumes of extraction buffer $(\mathrm{w} / \mathrm{v})$ containing $6 \mathrm{M}$ Urea, $2 \mathrm{M}$ thiourea, 2\% CHAPS and 0.5\% SDS in HPLC-grade water.

- Sonicate extracts briefly to disrupt DNA and leave on ice for 10 minutes, followed by centrifugation at $13,000 \times \mathrm{g}$ for 10 minutes at $4^{\circ} \mathrm{C}$ to pellet any insoluble material.

- To remove detergents that may interfere with iTRAQTM labeling, precipitate the proteins by the addition of 6 volumes of ice cold acetone overnight at $-20^{\circ} \mathrm{C}$.

- Pellet the acetone precipitates by centrifugation at $13,000 \times \mathrm{g}$ for 10 minutes at $4^{\circ} \mathrm{C}$ and then carefully remove and discard the supernatant.

- Allow the acetone to evaporate and resuspend the pellets in $6 \mathrm{M}$ Urea in $50 \mathrm{mM}$ triethylammonium bicarbonate (TEAB).*

- Determine the protein concentration in each sample and balance them carefully so that all samples contain the same amount of total protein. Each tag is capable of labeling $100 \mu \mathrm{g}$ of protein but it is best to aim for slightly less than this (i.e. no more than $85 \mu \mathrm{g}$ ) to allow for protein estimation errors. It is better to have slightly less protein than to have unlabeled peptides appearing in the mass spectrometer.

*It is important to avoid using buffers containing primary amines such as Tris buffers.

\section{2 iTRAQ $^{\mathrm{TM}}$ labeling}

- Perform reduction and alkylation steps using the reagents and instructions provided in the iTRAQ $^{\mathrm{TM}}$ labeling kit (AB Sciex). Detailed instructions can be found on the iTRAQTM ${ }^{\mathrm{TM}}$ chemistry reference guide, available on the AB Sciex website.

- Dilute the extracts in $50 \mathrm{mM}$ TEAB so that the urea concentration is less than $1 \mathrm{M}$ before the addition of trypsin.

- Digest with sequencing grade trypsin (1:20 w/w in $50 \mathrm{mM}$ TEAB) and incubate overnight at $37^{\circ} \mathrm{C}$. 
- Dry down digests in a vacuum centrifuge (in order to maximise iTRAQTM labeling efficiency the volume of each sample should be less than $50 \mu \mathrm{l})$.

- $\quad$ For the iTRAQTM labeling step follow instructions provided with the iTRAQTM reagents kit.

\subsection{Dimension I: Strong cation-exchange (SCX) chromatography}

- Pool the iTRAQTM-labeled peptides and make up to a total volume of $2.5 \mathrm{mls}$ in SCX buffer A (10mM phosphate, $\mathrm{pH} 3$ in $20 \%$ acetonitrile (MeCN) (Romil, UK)). The volume can be adjusted depending on the sample loop size. In order to ensure efficient binding to the SCX column, the final $\mathrm{pH}$ should as close to $\mathrm{pH} 3$ as possible. This can be achieved by the addition of orthophosphoric acid, whilst being careful to ensure that the overall phosphate concentration is not increased significantly (as this will also affect the binding efficiency).

- The following flow rates and conditions are optimized for use with a polysulfoethyl A, SCX column (300A, 5uM (PolyLC))

- Load the pooled peptides $(2.5 \mathrm{mls})$ onto a SCX column at a flow rate of 400ul/minute.

- Following sample injection wash the column with SCX buffer A until the baseline returns (this usually takes about 10-15 minutes).

- $\quad$ Run the gradient as follows: 0-50\% SCX buffer B (10mM phosphate, $1 \mathrm{M} \mathrm{NaCl}, \mathrm{pH} 3$ in $20 \%$ acetonitrile) over 25 minutes followed by a ramp up from $50 \%$ to $100 \%$ SCX buffer B over 5 minutes. Finally, wash the column in 100\% SCX buffer B for 5 minutes before equilibrating for 10 minutes with SCX buffer A.

- Collect 400ul fractions during the elution period (this usually yields about 20 fractions) and dry down completely in a vacuum centrifuge.

- Once dry, fractions can be stored at $-20^{\circ} \mathrm{C}$ until the next step.

*Polysulfoethyl A columns work best at ambient temperature so if you have a column oven you should remember to turn it off. Use of $0.1 \%$ TFA or high concentrations of formic acid in the mobile phase is not recommended so it is best to equilibrate the system with SCX buffer A before connecting the column.

\subsection{Dimension II: Reversed-phase chromatography}

Prior to mass spectrometry analysis, separate fractions by reversed-phase liquid chromatography. The following flow rates and conditions are optimised for use with a Pepmap C18 column, $200 \mu \mathrm{m} \times 15 \mathrm{~cm}$ (LC Packings).

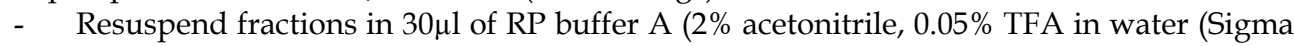
Chromasolv plus)). The order of fractions should be randomized in order to minimise effects from sample carry-over on the column.

- Perform reversed-phase chromatography separation of each fraction using the following gradient:

- Load fractions at a flow rate of $3 \mu \mathrm{l} /$ minute

- 10 minutes isocratic pre-run at $100 \%$ RP buffer A (0.05\% TFA in $2 \%$ acetonitrile in water),

- followed by a linear gradient from $0-30 \%$ RP buffer B $(0.05 \%$ TFA in $90 \%$ acetonitrile in water) over 100 minutes,

- followed by another linear gradient from 30\%-60\% RP buffer B over 35minutes. 
- Wash the column in $100 \%$ RP buffer B for a further 10 minutes, before a final equilibration step in $100 \%$ RP buffer A for 10 minutes.

- During the elution gradient, spot the eluate at 10 second intervals using a Probot (LC Packings) with a-cyano-4-hydroxycinnamic acid (CHCA) at 3mg/ml $(70 \%$ $\mathrm{MeCN}, 0.1 \% \mathrm{TFA}$ ) at a flow rate of $1.2 \mu \mathrm{l} / \mathrm{min}$.

\subsection{MALDI-TOF/TOF analysis}

Instrument settings will of course vary, depending on the type of MALDI TOF/TOF instrument used. Even two identical machines from the same vendor may need to be tuned and optimised slightly differently for optimal performance. For this reason, we have just highlighted some important general issues to consider, rather than suggesting exact instrument settings:

- Internal standards: MALDI TOF/TOF analysis of fractions from one reversed-phase LC run can take many hours and so it is important to be sure that the instrument is calibrated for the duration. By spiking a known standard into the MALDI matrix, with an internal calibration processing method specified, you can ensure that every fraction contains an internal reference. Glu-1-Fibrinopeptide is a common standard of choice, but it is important to ensure that you optimise the amount you spike in so that it is detectable in MS but not so abundant that it masks detection of your iTRAQ ${ }^{\mathrm{TM}}$ peptides.

- Ion statistics: in order to get good ion statistics for iTRAQ ${ }^{\mathrm{TM}}$ quantification it is important to acquire enough data from each spectrum. A total of 1000 shots per MS spectrum (with no stop conditions) and at least 2500 shots per MS/MS spectrum (no stop conditions) should be acquired.

- CID: The MS/MS acquisition operating mode should specify that collision-induced dissociated (CID).

- Precursor ion selection: it is important to set a limit on the number of precursors selected per spot for MS/MS analysis to enable you to get maximum of data out the spot, without burning the spot out. The order in which precursor ions are selected and analysed is also an important consideration. For an unbiased view of a proteome, a common approach is to acquire weaker precursors first (i.e. those with a lower signal/noise) as these are harder to get good fragmentation data from when spots start to burn out. Another approach is to skip a selected number of the strongest precursors in each spot, in an attempt to negate masking of low abundant peptides by those that are in high abundance.

\subsection{Bioinformatics}

There are several different software packages for performing database searches with iTRAQ ${ }^{\mathrm{TM}}$ data and many utilize MASCOT as the search engine. Software that supports iTRAQ $^{\mathrm{TM}}$ quantification will have several particular features: the ability to exclude the iTRAQTM reporter ion masses from the search, identify spectra with fixed iTRAQTM modifications (N-term (iTRAQTM), lysine (iTRAQ ${ }^{\mathrm{TM}}$ ) and methyl methanethiosulfonate (MMTS) modification of cysteine residues) and to apply correction factors to the peak areas of the iTRAQTM reporter peaks in peptide spectra identified. Although it is possible to manually calculate relative quantification, many software packages will also be able to perform this function automatically. GPS Explorer (AB Sciex), for example, is able to calculate iTRAQ ${ }^{\mathrm{TM}}$ protein and peptide ratios for all identified peptides in the database 
search. The ratio is calculated by selecting one tag as the reference mass and applying the following calculation: ratio $=$ fragment corrected area / reference corrected area. A normalization factor is usually also applied, and can be useful to normalize any deviances in iTRAQTM ratios due to unequal total protein in each sample set and impurities in the iTRAQ $^{\mathrm{TM}}$ tags themselves (normalized iTRAQ ${ }^{\mathrm{TM}}$ Ratio $=$ Ratio $/$ median $\mathrm{iTRAQ}^{\mathrm{TM}}$ Ratio of all found pairs).

\subsection{Validation}

Quantitative proteomic experiments such as iTRAQ ${ }^{\mathrm{TM}}$ are performed in an unbiased fashion and are intended to provide us with clues for further study, rather than to provide definitive answers. In order to extract useful information from the masses of data that are produced in iTRAQ ${ }^{\mathrm{TM}}$ experiments, it is important to have a system in place to interrogate and validate the data carefully. The approach used will depend on the aim of the experiment and the type of comparison that is being done (e.g. pair-wise, 4-plex but with samples in duplicate, 4-plex but with 4 different samples), but some points for consideration are listed:

- Cut-off values: data can be simplified dramatically by first applying a cut-off to remove proteins that are detected with less than a certain number of peptides, and also with less than a certain total ion score confidence interval. A good starting point is to apply a very stringent filter and reduce if necessary (i.e. discard proteins detected with less than $95 \%$ total ion score confidence interval and less than 2 peptides). The data may then be filtered further to leave proteins that up- or down-regulation by a defined minimum amount.

- Statistics: the iTRAQTM protein ratio is an average ratio, calculated using the individual peptide ratios for each peptide used to identify the protein. One inaccurate peptide ratio may dramatically skew the average ratio for the whole protein, so for validation, it is important to also look closely at the individual peptide ratios for each protein. One way to do this is to perform statistical tests that compare normalized peptide ratios from each sample in a pair-wise fashion.

- Biochemistry: providing antibodies are available, iTRAQTM-predicted changes in protein levels can be confirmed by biochemical methods such as western blotting, ELISA or immunohistochemistry.

- Mass spectrometry approaches: although they often take time to optimise, high through-put mass spectrometry-based assays such as multiple-reaction monitoring (MRM) can be especially useful for validating biomarkers, especially when antibodies are not available (Anderson and Hunter, 2006).

\section{Applications of iTRAQ ${ }^{T M}$ in medical research}

Since 2005, several hundred papers have been published that describe applications of iTRAQ ${ }^{\mathrm{TM}}$ to many areas of medical research, including, but not limited to: various cancers, neurodegenerative disorders, liver and kidney problems, pre-eclampsia, diabetes, hostpathogen interactions, pancreatitis and autoimmune disorders. The majority of these studies were designed to discover biomarkers in order to understand disease mechanisms, to improve methods for early and sensitive diagnosis, to identify potential therapeutic targets, or to understand the mechanism of action of drugs. A smaller number of studies also attempted to identify biomarkers that could be useful for predicting the prognosis of patients with various types of cancer (Rehman et al., 2008; Matta et al., 2009; Tripathi et al., 2010). 


\subsection{Examples of clinically-relevant iTRAQ ${ }^{T M}$ applications}

An early, clinically-relevant application of iTRAQ ${ }^{\mathrm{TM}}$ was in 2005 when DeSouza et al. identified nine potential biomarkers for endometrial cancer. In 2007, they performed a much larger 40-sample iTRAQ ${ }^{\mathrm{TM}}$ study in an attempt to verify these earlier findings, and found that none of the nine previously identified potential biomarkers had the sensitivity and specificity to be used individually to discriminate between normal and cancer samples. They did however, find that a panel of three of these proteins: pyruvate kinase, chaperonin 10 and $\mathrm{a}_{1}$-antitrypsin, gave good results with sensitivity, specificity, predictive value and positive predictive value of 0.95 in a logistic regression analysis (DeSouza et al., 2007). Glen et al. (2008) used iTRAQ ${ }^{\mathrm{TM}}$ to identify tumor regression antigen, gp96, as a highly-significant marker to distinguish benign from malignant prostate cancers. Rudrabhatla et al. (2010) used iTRAQTM to identify amino-acid residues on neurofilament proteins that were more highlyphosphorylated in Alzheimer Disease patients, while Abdi et al. (2006) reported potential biomarkers in cerebrospinal fluid to distinguish Alzheimer's disease, Parkinson's disease and dementia with Lewy body (DLB). The greatest improvement of iTRAQ ${ }^{\mathrm{TM}}$ over 2D-gels is observed with membrane proteins and Han et al. (2008) were able to use it to identify potential therapeutic targets for autosomal dominant polycystic kidney disease by comparing kidney plasma membranes from wild-type and diseased mouse models. Grant $e t$ al. (2009) used iTRAQTM to study the effects of aging on the proteome of cardiac left ventricles and obtain clues to the mechanism of loss of diastolic function with age. Pendyala et al. (2010) used iTRAQ ${ }^{\mathrm{TM}}$ to show that the vitamin E binding protein, afamin, is downregulated after viral infection in a study of HIV-1-associated neurocognitive disorder (HAND). Although serum samples present a problem for iTRAQTM because of high concentrations of a few major proteins, the work of Dwivedi et al. (2009) illustrates how this was overcome in a study of the proteomic effects of anti-TNF-alpha treatment of rheumatoid arthritis patients. These examples illustrate the wide variety of applications of iTRAQ ${ }^{\mathrm{TM}}$ to the most common of all human health problems.

\subsection{Considerations when comparing patients}

With adequate care, meaningful iTRAQ ${ }^{\mathrm{TM}}$ comparisons of diseased versus control tissues are possible, as illustrated in the previous section. However, iTRAQTM comparisons of patient-derived material such as skin fibroblasts, serum, CSF, saliva and other tissue types present additional problems: in particular, they may display differences due to the age, sex or genetic background of the original donors, rather than specifically due to a genetic mutation or disease state. For example, Miike et al. (2010) used iTRAQTM to show that there are gender differences in serum protein composition and Truscott et al. (2010) used iTRAQ ${ }^{\mathrm{TM}}$ analysis of human lenses to show that protein-membrane interactions change significantly with age. Our own work on the inherited neuromuscular disease, spinal muscular atrophy (SMA), can also be used to illustrate some of the issues associated with comparing patient-derived material. The widely-used GM03813 primary skin fibroblasts from a spinal muscular atrophy (SMA) patient (Coriell Cell Repositories) have a genetic mutation that causes a large reduction in the levels of SMN protein. Using iTRAQTM labeling technology, followed by two-dimensional liquid chromatography and MALDI TOF/TOF analysis, we quantitatively compared the proteomes of a variety of SMA and control skin fibroblast lines. Comparison of SMA patient fibroblasts with an unrelated control of similar age showed that the largest differences reflected their different genotypes (i.e. HLA and MHC antigens). This was largely overcome by comparison with fibroblasts 
from the child's mother, an unaffected SMA carrier (GM03814). However, myogenic cells present in one primary cell line (GM03813) but not the other resulted in an apparent increase in the myoblast-specific protein, desmin in the SMA cells (Figure 3). This observation enabled us to obtain a myoblast-free fibroblast population for further studies by immortalizing and cloning this primary cell line (Fuller et al, 2010).

\section{MS/MS spectrum for desmin peptide: DGEVVSEATQQQHEVL}

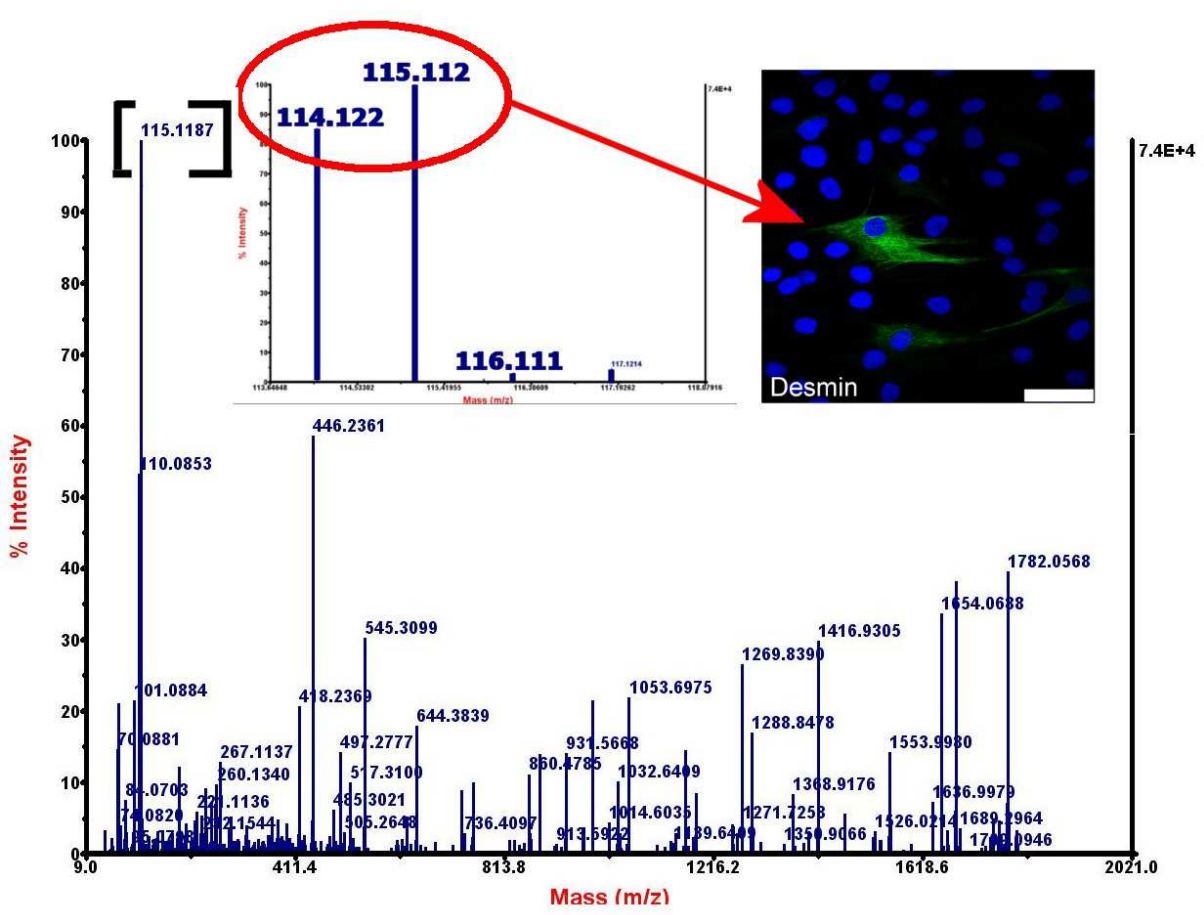

Fig. 3. A non-homogeneous patient cell line gave false positive iTRAQTM results.

Peptides from an SMA patient cell line were analysed in duplicate (labeled with 114 and 115 iTRAQ tags) and compared to a control cell line, also analysed in duplicate (labeled with 116 and 117 iTRAQ tags). An example MS/MS spectrum is shown for a peptide identified as the muscle-specific protein, desmin. The image inset on the top left is an expanded MS/MS spectrum showing that only the 114 and 115 reporter ions were detected. The suspicion that the SMA patient cell line contained myogenic cells, absent from control cells, was confirmed by immunofluorescence microscopy with an anti-desmin antibody (green in the inset image).

\subsection{Proteomic effects of drug treatments}

In-vivo studies that monitor the therapeutic effect of drugs on patients over time are very complicated to design and involve considering many factors such as: the time of day tissue sample is taken, change in diet, infection and secondary effects caused by the disease or 
aging. However, an iTRAQ ${ }^{\mathrm{TM}}$ comparison of a single cell line, with and without a drug, is a much more straightforward general approach to understanding the mechanisms of action of drugs and their side-effects. Wang et al. (2010) used this approach to examine the effect of the beta blocker Carvedilol in vascular smooth muscle cells and found 13 proteins that were altered in expression. Another example is the work of Bai et al. in 2010, when they used iTRAQ ${ }^{\mathrm{TM}}$ to look at the effects of the anti-coagulation drug warfarin on HepG2 cells and identified two proteins, DJ-1 and 14-3-3 Protein, that were altered in expression.

We recently used this approach to identify possible side-effects of drugs for spinal muscular atrophy (SMA) (Fuller et al., 2010). Valproate is commonly used as an anticonvulsant in epilepsy and as a mood stabilizer, but its long-term side-effects can include bone loss. As a histone deacetylase (HDAC) inhibitor, valproate has also been considered for treatment of SMA. Using iTRAQ labeling, we performed a quantitative comparison of the proteome of an SMA skin fibroblast cell line, with and without valproate treatment. The most striking change was a reduction in collagens I and VI, while over 1000 other proteins remained unchanged. The collagen-binding glycoprotein, osteonectin (SPARC, BM-40) was one of the few other proteins that were significantly reduced by valproate treatment. Collagen I is the main protein component of bone matrix and osteonectin has a major role in bone development, so the results suggest a possible molecular mechanism for bone loss following long-term exposure to valproate. An example MS/MS spectrum showing reduction of a collagen I peptide after treatment valproate is shown in Figure 4.

MS/MS spectrum for collagen I peptide: GEPGPVGVQGPPGPAGEEGKR

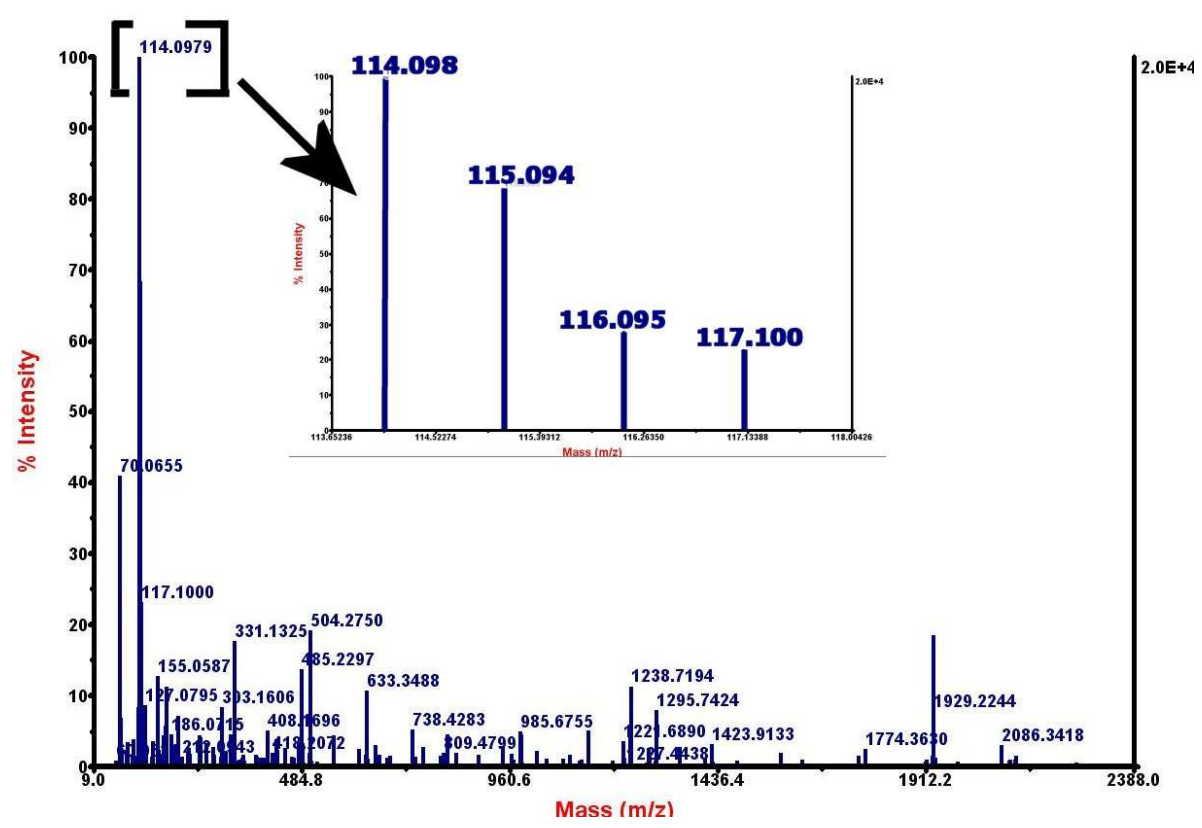

Fig. 4. Reduction of collagen I after treatment with valproate 
Peptides from an SMA patient cell line treated with valproate were analysed in duplicate (labeled with 116 and 117 iTRAQ tags) and compared to the same cell line without valproate treatment, also analysed in duplicate (labeled with 114 and 115 iTRAQ tags). An example MS/MS spectrum is shown for a peptide identified as collagen. The image inset on the top left is an expanded MS/MS spectrum showing that the 116 and 117 iTRAQ reporter ions were much lower in intensity than the 114 and 115 iTRAQ reporter ions. Biochemical studies confirmed that collagen I is reduced after treatment with valproate (Fuller et al., 2010).

\subsection{Bringing biomarkers to the bedside}

Although there are many reports in the literature using iTRAQ ${ }^{\mathrm{TM}}$ to identify potential biomarkers of disease, very few biomarkers ever get fully validated to the stage where they can be used in a clinical setting to benefit patients. The low rate of transition from the laboratory to the clinic is something that is seen with biomarkers in general, and not just those identified by iTRAQ ${ }^{\mathrm{TM}}$ or other quantitative proteomic approaches. In order for a new biomarker to be introduced into routine clinical practice, a slow and detailed process is required to obtain evidence that it is robust, precise and reproducible, in addition to demonstrating that it will improve patient management and outcome, and have audit and cost benefits (reviewed in detail by Sturgeon et al., 2010).

\section{Summary and future prospects}

Without a doubt, iTRAQTM labeling of peptides has had a significant impact on the development of quantitative proteomics over the last 8 years. The ability to multiplex and analyze up to 8 samples within the same experiment adds flexibility to the experimental design without complicating MS data analysis. In 2008, Thermo Fisher in-licensed an isobaric mass tagging technology called TMT, which can be multiplexed to allow analysis of up to 6 samples, further confirmation of the wide acceptance of this technique.

The discovery of new biomarkers will help us to understand disease mechanisms and prognosis better, to improve methods for early and sensitive diagnosis, to identify therapeutic targets, or to understand the mechanism of action of drugs. Although iTRAQTM has been very useful for potential biomarker discovery, issues regarding analytical and experimental variability need to be addressed before the benefit of iTRAQTM reaches routine analysis in the clinical laboratory. With further developments to address issues affecting accuracy of iTRAQ quantification and improving data analysis tools, medical research may benefit greatly from iTRAQ-based quantitative proteomics over the coming years.

\section{Acknowledgements}

Our own research was supported by grants from the Jennifer Trust for SMA, the Muscular Dystrophy Association (USA) and the RJAH Institute of Orthopaedics, UK.

\section{References}

Abdi, F., Quinn, J.F., Jankovic, J., McIntosh, M., Leverenz, J.B., Peskind, E., Nixon, R., Nutt, J., Chung, K., Zabetian, C., Samii, A., Lin, M., Hattan, S., Pan, C., Wang, Y., Jin, J., Zhu, D., Li. G.J., Liu, Y., Waichunas, D., Montine, T.J. \& Zhang, J. (2006). Detection of biomarkers with a multiplex quantitative proteomic platform in cerebrospinal 
fluid of patients with neurodegenerative disorders. J Alzheimers Dis, Vol.9, No.3, (December 2006), pp.293-348.

Anderson, L. \& Hunter, C.L. (2006). Quantitative mass spectrometric multiple reaction monitoring assays for major plasma proteins. Mol Cell Proteomics, Vol.5, No.4, (April 2006), pp.573-88.

Arntzen, M.Ø., Koehler, C.J., Barsnes, H., Berven, F.S., Treumann, A. \& Thiede, B. (2011). IsobariQ: software for isobaric quantitative proteomics using IPTL, iTRAQ, and TMT. J Proteome Res, Vol.10, No.2, (February 2011), pp.913-20.

Bai, J., Sadrolodabaee, L., Ching, C.B., Chowbay, B. \& Ning Chen, W. (2010). A comparative proteomic analysis of HepG2 cells incubated by $S(-)$ and $R(+)$ enantiomers of anticoagulating drug warfarin. Proteomics. Vol.10, No.7, (April 2010), pp.1463-73.

Bantscheff, M., Boesche, M., Eberhard, D., Matthieson, T., Sweetman, G. \& Kuster, B. (2008). Robust and sensitive iTRAQ quantification on an LTQ Orbitrap mass spectrometer. Mol Cell Proteomics,Vol.7, No.9, (September 2008), pp.1702-13.

Choe, L., D'Ascenzo, M., Relkin, N.R., Pappin, D., Ross, P., Williamson, B., Guertin, S., Pribil, P. \& Lee, K.H. (2007). 8-plex quantitation of changes in cerebrospinal fluid protein expression in subjects undergoing intravenous immunoglobulin treatment for Alzheimer's disease. Proteomics, Vol.7, No.20, (October 2007), pp.3651-60.

DeSouza, L., Deihl, G., Rodrigues, M.J., Guo, J., Romaschin, A.D., Colgan, T.J. \& Siu, K.W. (2005). Search for cancer markers from endometrial tissues using differentially labeled tags iTRAQ and cICAT with multidimensional liquid chromatography and tandem mass spectrometry. Journal of Proteome Research, Vol.4, No.2, (March-April 2005), pp.377-86.

DeSouza, L.V., Grigull, J., Ghanny, S., Dube, V., Romaschin, A.D., Colgan T.J. \& Siu, K.W. (2007). Endometrial carcinoma biomarker discovery and verification using differentially tagged clinical samples with multidimensional liquid chromatography and tandem mass spectrometry. Molecular and Cellular Proteomics, Vol.6, No.7, (July 2007), pp.1170-82.

Dwivedi, R.C., Dhindsa, N., Krokhin, O.V., Cortens, J., Wilkins, J.A. \& El-Gabalawy, H.S. (2009). The effects of infliximab therapy on the serum proteome of rheumatoid arthritis patients. Arthritis Res Ther, Vol.11, No.2, R32.

Fuller, H.R., Man, N.T., Lam, le. T., Shamanin, V.A., Androphy, E.J. \& Morris, G.E. (2010). Valproate and bone loss: iTRAQ proteomics show that valproate reduces collagens and osteonectin in SMA cells. Journal of Proteome Research, Vol.9, No.8, (August 2010),pp.4228-33.

Glen, A., Gan, C.S., Hamdy, F.C., Eaton, C.L., Cross, S.S., Catto, J.W., Wright, P.C. \& Rehman, I. (2008). iTRAQ-facilitated proteomic analysis of human prostate cancer cells identifies proteins associated with progression. J Proteome Res, Vol.7, No.3, (March 2008), pp.897-907.

Grant, J.E., Bradshaw, A.D., Schwacke, J.H., Baicu, C.F., Zile, M.R. \& Schey, K.L. (2009). Quantification of protein expression changes in the aging left ventricle of Rattus norvegicus. J Proteome Res. Vol.8, No.9, (September 2009), pp.4252-63.

Gygi, S.P., Rist, B., Gerber, S.A., Turecek, F., Gelb, M.H. \& Aebersold, R. (1999). Quantitative analysis of complex protein mixtures using isotope-coded affinity tags. Nature Biotechnology, Vol. 17, No.10, (October 1999), pp. 994-9. 
Han, C.L., Chien, C.W., Chen, W.C., Chen, Y.R., Wu, C.P., Li, H. \& Chen, Y.J. (2008). A multiplexed quantitative strategy for membrane proteomics: opportunities for mining therapeutic targets for autosomal dominant polycystic kidney disease. Mol Cell Proteomics. Vol.7, No.10, (October 2008), pp.1983-97.

Issaq, H.J., Veenstra, T.D. (2008). Two-dimensional polyacrylamide gel electrophoresis (2DPAGE): advances and perspectives. Biotechniques, Vol.44, No.5, pp.697-700.

Karp, N.A., Huber, W., Sadowski, P.G., Charles, P.D., Hester, S.V. \& Lilley, K.S. (2010). Addressing accuracy and precision issues in iTRAQ quantitation. Mol Cell Proteomics. Vol.9, No.9, (September 2010), pp.1885-97.

Köcher, T., Pichler, P., Schutzbier, M., Stingl, C., Kaul, A., Teucher, N., Hasenfuss, G., Penninger, J.M. \& Mechtler K. (2009). High precision quantitative proteomics using iTRAQ on an LTQ Orbitrap: a new mass spectrometric method combining the benefits of all. J Proteome Research, Vol.8, No.10, (October 2009), pp. 4743-52.

Kuzyk, M.A., Ohlund, L.B., Elliott, M.H., Smith, D., Qian, H., Delaney, A., Hunter, C.L. \& Borchers, C.H. (2009) A comparison of MS/MS-based, stable-isotope-labeled, quantitation performance on ESI-quadrupole TOF and MALDI-TOF/TOF mass spectrometers. Proteomics, Vol.9, No.12, (June 2009), pp.3328-3340.

Matta, A., Tripathi, S.C., DeSouza, L.V., Grigull, J., Kaur, J., Chauchan, S.S., Thakar, A., Shukla, N.K., Duggal, R., DattaGupta, S., Ralhan, R., Michael Siu, K.W. (2009). Heterogeneous ribonucleprotein $\mathrm{K}$ is a marker of oral leukoplakia and correlates with poor prognosis of squamous cell carcinoma. Int J Cancer, Vol.125, No.6, (September 2009), pp.1398-406.

Miike, K., Aoki, M., Yamashita, R., Takegawa, Y., Saya, H., Miike, T. \& Yamamura, K. (2010). Proteome profiling reveals gender differences in the composition of human serum. Proteomics, Vol.10, No.14, (July 2010), pp.2678-91.

Ong, S.E., Blagoev, B., Kratchmarova, I., Kristensen, D.B., Steen, H., Pandey, A. \& Mann, M. (2002). Stable isotope labeling by amino acids in cell culture, SILAC, as a simple and accurate approach to expression proteomics. Molecular and Cellular Proteomics, Vol.1, No.5, (May 2002), pp.376-86.

Ow, S.Y., Salim, M., Noirel, J., Evans, C., Rehman, I. \& Wright, P.C. (2009). iTRAQ underestimation in simple and complex mixtures: "the good, the bad and the ugly". J Proteome Res, Vol.8, No.11, (November 2009), pp.5347-55.

Ow, S.Y., Salim, M., Noirel, J., Evans, C. \& Wright, P.C. (2011). Minimising iTRAQ ratio compression through understanding LC-MS elution dependence and highresolution HILIC fractionation. Proteomics. Vol.11, No.11, (June 2011), pp. 2341-6.

Pendyala, G., Trauger, S.A., Siuzdak, G. \& Fox, H.S. (2010). Quantitative plasma proteomic profiling identifies the vitamin $\mathrm{E}$ binding protein afamin as a potential pathogenic factor in SIV induced CNS disease. J Proteome Res, Vol.9, No.1, (January 2010), pp.352-8.

Ross, P. L., Huang, Y.N., Marchese, J.N., Williamson, B., Parker, K., Hattan, S., Khainovski, N., Pillai, S., Dey, S., Daniels, S., Purkayastha, S., Juhasz, P., Martin, S., BartletJones, M., He, F., Jacobson, A. \& Pappin, D.J. (2004). Multiplexed Protein Quantitation in Saccharomyces cerevisiae Using Amine-reactive Isobaric Tagging Reagents. Molecular and Cellular Proteomics, Vol.3, No.12, (December 2004), pp. 115469. 
Rudrabhatla, P., Grant, P., Jaffe, H., Strong, M.J. \& Pant, H.C. (2010). Quantitative phosphoproteomic analysis of neuronal intermediate filament proteins (NF-M/H) in Alzheimer's disease by iTRAQ. FASEB J, Vol.24, No.11, (November 2010), pp.4396-407.

Scheri, R.C., Lee, J., Curtis, L.R. \& Barofsky, D.F. (2008). A comparison of relative quantification with isobaric tags on a subset of the murine hepatic proteome using electrospray ionization quadrupole time-of-flight and matrix-assisted laser desorption/ionization tandem time-of-flight. Rapid Commun Mass Spectrom, Vol.22, No.20, (October 2008), pp.3137-46.

Shirran, S.L. \& Botting, C.H. (2010) A comparison of the accuracy of iTRAQ quantification by nLC-ESI MSMS and nLC-MALDI MSMS methods. J. Proteomics, Vol.73, No.7, (May 2010), pp. 1391-403.

Sturgeon, C., Hill, R., Hortin, G.L. \& Thompson, D. (2010). Taking a new biomarker into routine use - A perspective from the routine clinical biochemistry laboratory. Proteomics Clin Appl, Vol.4, No.12, (December 2010), pp. 892-903.

Tripathi, S.C., Matta, A., Kaur, J., Grigull, J., Chauchan, S.S., Thakar, A., Shukla, N.K., Duggal, R., DattaGupta, S., Ralhan, R., Michael Siu, K.W. (2010) Nuclear S100A7 is associated with poor prognosis in head and neck cancer. PLos One, Vol.5, No.8, (August 2010), e11939.

Truscott, R.J., Comte-Walters, S., Ablonczy, Z., Schwacke, J.H., Berry, Y., Korlimbinis, A., Friedrich, M.G. \& Schey, K.L. (2010). Tight binding of proteins to membranes from older human cells. Age (Dordr), 2010 Dec 23. [Epub ahead of print].

Wang, M., Wang, X., Ching, C.B. \& Chen, W.N. (2010). Proteomic profiling of cellular responses to Carvedilol enantiomers in vascular smooth muscle cells by iTRAQcoupled 2-D LC-MS/MS. J Proteomics, Vol.73, No.8, (June 2010), pp. 1601-11.

Washburn, M.P., Wolters, D. \& Yates, J.R. 3rd. (2001). Large-scale analysis of the yeast proteome by multidimensional protein identification technology. Nature Biotechnology, Vol.19, No.3, (March 2001), pp.242-7.

Wu, W.W., Wang, G., Baek, S.J., Shen, R-F. (2005). Comparative study of three proteomic quantitative methods, DIGE, cICAT, and iTRAQ, using 2D gel- or LC-MALDI TOF/TOF. J Proteome Research, Vol.5, No.3, pp.651-658.

Yang, E.C., Guo, J., Diehl, G., DeSouza, L., Rodrigues, M.J., Romaschin, A.D., Colgan, T.J. \& Siu, K.W. (2004). Protein expression profiling of endometrial malignancies reveals a new tumor marker: chaperonin 10. J Proteome Res, Vol.3, No.3, (May-June 2004), pp.636-43.

Yang, Y., Zhang, S., Howe, K., Wilson, D.B., Moser, F. \& Irwin, D. (2007). Comparison of nLC-ESI-MS/MS and nLC-MALDI-MS/MS for Gel-LC-based protein identification and iTRAQ-based shotgun quantitative proteomics. J Biomol Tech, Vol. 18, No.4, (September 2007), pp.226-37.

Zieske, L.R. (2006). A perspective on the use of iTRAQ ${ }^{\mathrm{TM}}$ reagent technology for protein complex and profiling studies. Journal of Experimental Botany, Vol.57, No.7, (March 2006), pp.1501-08.

Zhang, Y., Ficarro, S.B., Li, S. \& Marto, J.A. (2009). Optimized Orbitrap HCD for quantitative analysis of phosphopeptides. J Am Soc Mass Spectrom, Vol.20, No.8, (August 2009), pp.1425-34. 


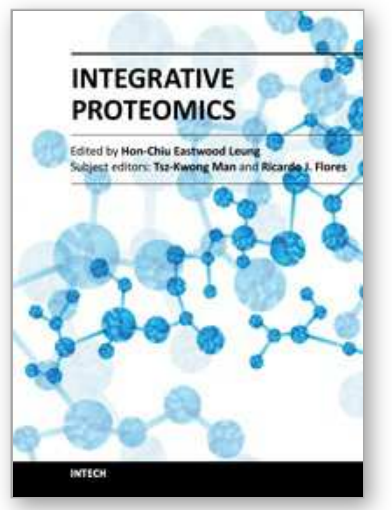

\author{
Integrative Proteomics \\ Edited by Dr. Hon-Chiu Leung
}

ISBN 978-953-51-0070-6

Hard cover, 442 pages

Publisher InTech

Published online 24, February, 2012

Published in print edition February, 2012

Proteomics was thought to be a natural extension after the field of genomics has deposited significant amount of data. However, simply taking a straight verbatim approach to catalog all proteins in all tissues of different organisms is not viable. Researchers may need to focus on the perspectives of proteomics that are essential to the functional outcome of the cells. In Integrative Proteomics, expert researchers contribute both historical perspectives, new developments in sample preparation, gel-based and non-gel-based protein separation and identification using mass spectrometry. Substantial chapters are describing studies of the sub-proteomes such as phosphoproteome or glycoproteomes which are directly related to functional outcomes of the cells.

Structural proteomics related to pharmaceutics development is also a perspective of the essence.

Bioinformatics tools that can mine proteomics data and lead to pathway analyses become an integral part of proteomics. Integrative proteomics covers both look-backs and look-outs of proteomics. It is an ideal reference for students, new researchers, and experienced scientists who want to get an overview or insights into new development of the proteomics field.

\title{
How to reference
}

In order to correctly reference this scholarly work, feel free to copy and paste the following:

H. R. Fuller and G. E. Morris (2012). Quantitative Proteomics Using iTRAQ Labeling and Mass Spectrometry, Integrative Proteomics, Dr. Hon-Chiu Leung (Ed.), ISBN: 978-953-51-0070-6, InTech, Available from: http://www.intechopen.com/books/integrative-proteomics/quantitative-proteomics-using-itraq-labeling-andmass-spectrometry

\section{INTECH}

open science | open minds

\section{InTech Europe}

University Campus STeP Ri

Slavka Krautzeka 83/A

51000 Rijeka, Croatia

Phone: +385 (51) 770447

Fax: +385 (51) 686166

www.intechopen.com

\section{InTech China}

Unit 405, Office Block, Hotel Equatorial Shanghai

No.65, Yan An Road (West), Shanghai, 200040, China 中国上海市延安西路65号上海国际贵都大饭店办公楼 405 单元

Phone: +86-21-62489820

Fax: +86-21-62489821 
(C) 2012 The Author(s). Licensee IntechOpen. This is an open access article distributed under the terms of the Creative Commons Attribution 3.0 License, which permits unrestricted use, distribution, and reproduction in any medium, provided the original work is properly cited. 